\title{
ANALYSIS OF INCREMENTAL SHEET FORMING
}

\section{PROCESS THROUGH SIMULATION}

\section{YOGESH KUMAR \& SANTOSH KUMAR}

Department of Mechanical Engineering, Indian Institute of Technology (BHU), Varanasi, Uttar Pradesh, India

Incremental sheet forming (ISF) process is a flexible manufacturing process to produce complex $3 D$ products at reasonable manufacturing cost. An advantage of ISF is the improved formability than traditional sheet forming processes. The traditional sheet forming process requires dedicated tools (i.e. die and punch). However, ISF does not require any dedicated tool. In the current work, analysis of incremental sheet forming process through simulation has been done to predict the forming forces, energy requirements, effective stresses, and total forming forces on the sheet. The geometry accuracy of the product is found to be satisfactory. The results of simulation analysis may guide in developing an incremental sheet forming machine setup.
\end{abstract}

KEYWORDS: Incremental Sheet Forming, Die-Less Forming \& Advance Sheet Forming

Received: Mar 22, 2018; Accepted: Apr 12, 2018; Published: Apr 27, 2018; Paper Id.: IJMPERDJUN201816

\section{INTRODUCTION AND LITERATURE REVIEW}

Incremental sheet forming (ISF) process is a flexible manufacturing process to produce complex 3D products at reasonable manufacturing cost. Incremental sheet forming has shown improved formability as compared to the traditional sheet forming processes such as stamping. The traditional sheet forming process requires dedicated tools (i.e. die and punch). However, ISF does not require any dedicated tool. The conventional forming process requires dedicated tools (i.e. die and punch). The Incremental sheet forming is capable to meet the market demand of low cost 3D complex product. The Incremental forming processes are broadly classified into two categories [Kumar et al., 2015]: (i) Conventional Incremental Sheet Forming (CISF), (ii) Hybrid Incremental Sheet Forming (HISF).

In conventional Incremental Sheet forming process, the deforming tool moves over the surface of the sheet and results in the final shape. The Conventional Incremental forming process can be further classified as (a) Single Point Incremental Forming SPIF, also known as Negative die-less Forming (Figure 1) \& (b) Two-Point Incremental Forming, TPIF or Positive Die less Forming (Figure 2) [Kumar et al., 2015].

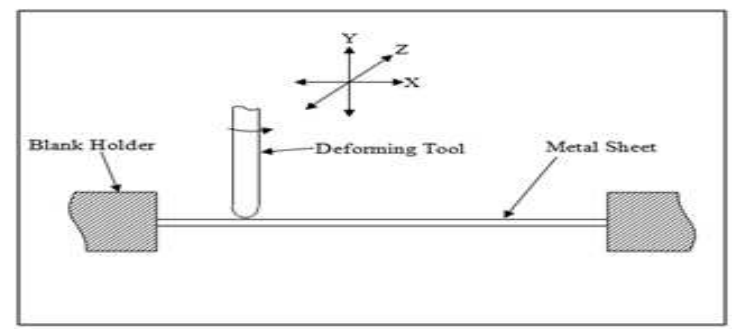

Figure 1: Single Point Incremental Forming (SPIF) [Kumar et al., 2015] 


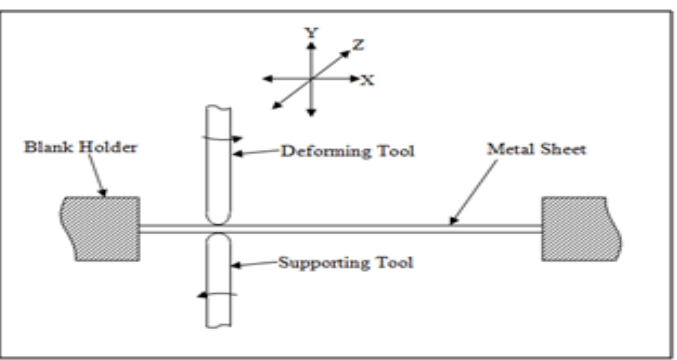

Figure 2: Two Point Incremental Forming (TPIF)

[Kumar et al., 2015].

Hybrid Incremental forming sheet forming processes are the modified form of conventional incremental forming. In these processes deforming tool moves over the surface of sheet metals while the other side of the surface of sheet metals is supported by Pressurized Hydraulic Fluid, Partial Die or Full Die to get the desired Shape and Size. Hybrid Incremental Forming Processes are further classified as (a) Single Point Incremental Forming with Hydraulic Fluid also known as Single Point Incremental Hydro-Forming (Fig. 3), (b) Two-Point Incremental Forming with Partial Die (Fig. 4) and (c) Two-Point Incremental Forming with Full Die (Fig. 5).

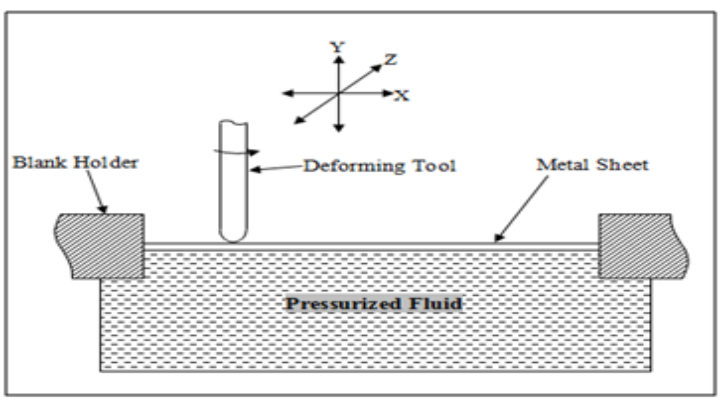

Figure 3: Single Point Incremental Hydro-Forming (SPIHF) [Kumar et al., 2015].

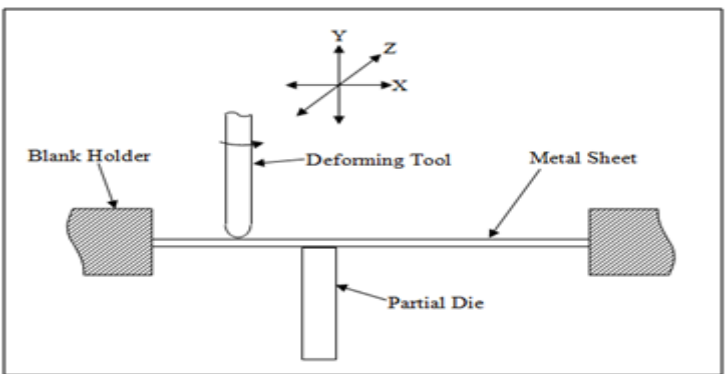

Figure 4: Two Point Incremental Forming with Partial Die (TPIFPD) [Kumar et al., 2015].

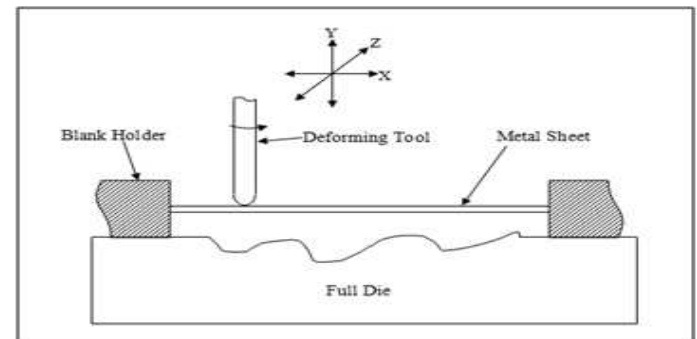

Figure 5: Two Point Incremental Forming with Full Die (TPIFFD) [Kumar et al., 2015]. 
Hesse et al. (2017) determined the influencing parameters and derivation of a model by means of simulative and experimental investigations. Okada et al. (2018) developed an incremental forming method for carbon fiber reinforced thermoplastics (CFRTP's) using an optical heating system. Ai et al. (2017) presented a new analytical model which is focused on investigating the deformation stability and its effect on the metal sheet fracture. Li et al. (2017) presented a new type of sheet metal forming technology using ultrasonic vibration applied to SPIF (single point incremental forming) process. Min et al. (2018) found that the poor geometric accuracy of work pieces plagues single-point incremental forming (SPIF) due to lack of support and unwanted plastic deformation. Suresh et al. (2017) presented some of the experimental studies in multi-stage incremental forming of steel sheets to get steep wall angles. Borrego et al. (2016) investigated the ability of the SPIF process to perform hole-flanges in a single stage, contributing to a better understanding of the formability of metal sheet. Centeno et al. (2012) found that hole-flanging by incremental forming gives rise to a new mode of deformation, not found in conventional incremental forming of sheet metal blanks without pre-cut holes, and to failure by fracture without previously localized necking. Durante et al. (2018) conducted different experimental tests, involving different tool types (with fixed and rotating end) and tool paths (unidirectional and alternate), to determine their influence on the material formability, twisting, elastic spring back, forming forces, sheet thinning and surface roughness. Cao et al. (2016) investigated the stress distribution and strain variation by the analytical approach and numerical simulation. Baruah et al. (2017) identified that lubrication has the highest contributing factor for all the three directions and feed rate as the least. Vertical step down and speed are the second and third contributing parameters.

\section{ELEMENTS OF INCREMENTAL SHEET FORMING PROCESS}

The main elements of the Incremental sheet forming process are (1) Sheet Metal Bank (2) Blank holding arrangement (3) Forming Tool, (4) CNC Machine. The Sheet blank of 125 diameters and 2 mm thickness has been chosen for the current simulation study. The blank- holding arrangement and forming tool as shown in Fig 7 has been developed. The simulation has been carried out in Deform 3D. The optimum number of meshes of the metal sheet is 100000 mesh elements.

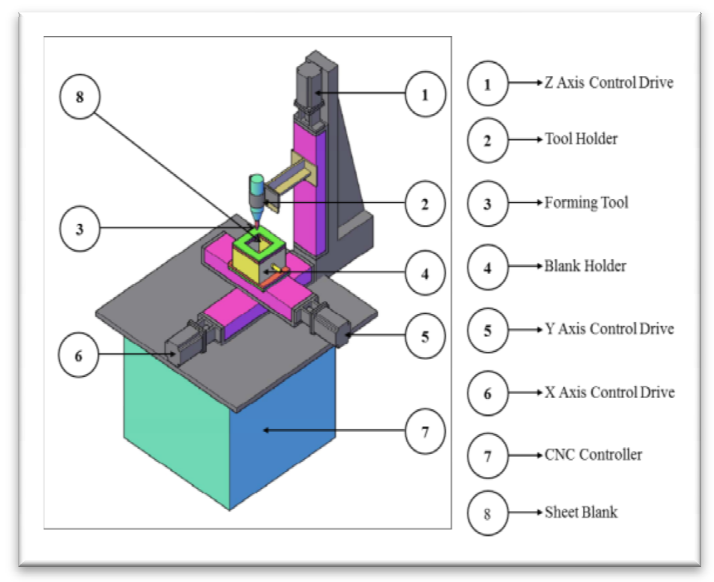

Figure 6: Elements of Incremental Sheet Forming Process 


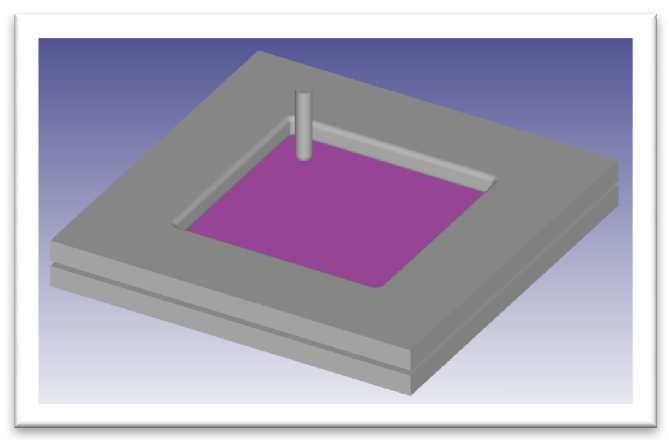

Figure 7: Blank Holding \& Forming Tool

\section{SIMULATION RESULTS}

The simulation was done using Deform 3D and it took approximately 20 days to complete the simulation. The final shape of the product obtained by simulation is shown in Fig 8.

The simulation results obtained are (1) load prediction, i.e. the forming forces, (2) Energy requirements, (3) Effective stresses (4) Total force on the sheet, and (5) geometric accuracies. The same are discussed in the current section.

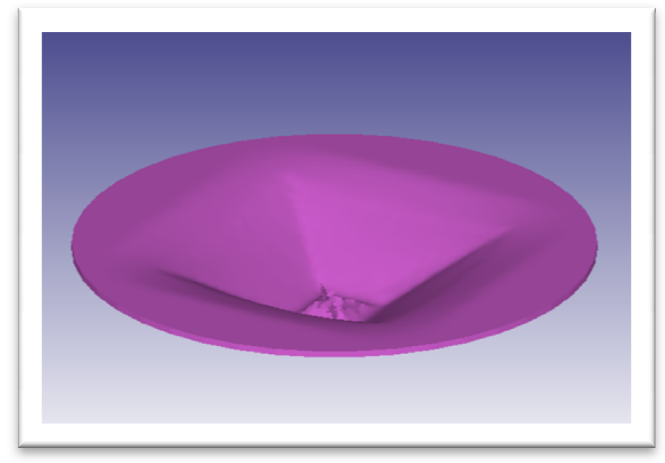

Figure 8: Final Product

\section{Load Predictions}

The forming forces (load) have been predicted from simulation results. The load predicted in $\mathrm{X}, \mathrm{Y}$ and $\mathrm{Z}$ direction in shown in Fig. 9, $10 \& 11$. The forming force requirement is very low. It increases at very-2 slow rate due to strain - hardening effect on the sheet.

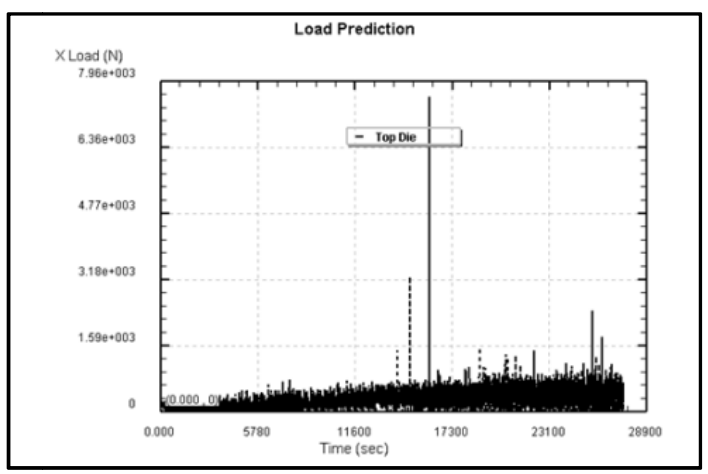

Figure 9: Load Prediction in X - Direction 


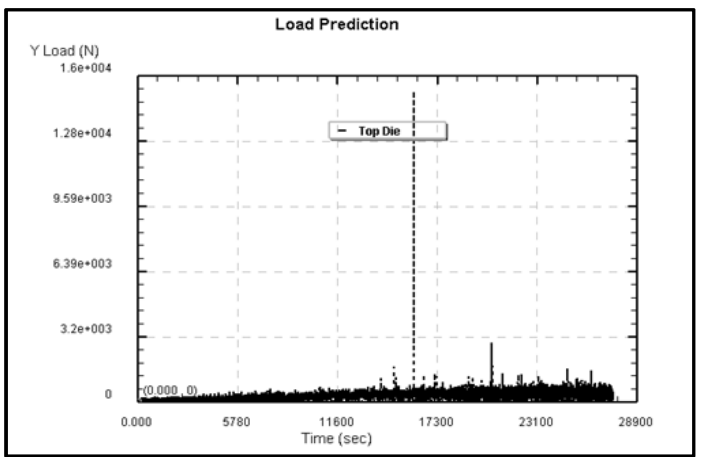

Figure 10: Load Prediction in Y - Direction

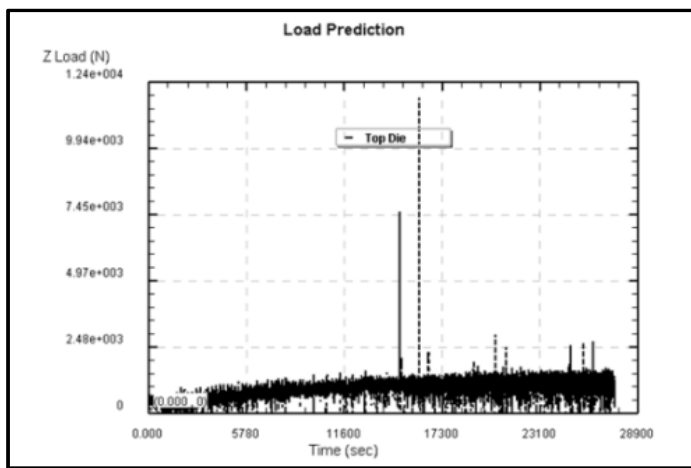

Figure 11: Load Prediction in Z - Direction

The forming force $\mathrm{s}$ in incremental sheet forming is very low when as compared to forming forces in traditional forming processes. The main reason for very low forming forces is the localized deformation in a small contact area between in tool \& sheet blank.

\section{Energy Requirements}

The total energy requirement has been predicted as shown in Fig 12. The energy requirement is linearly increasing with time. The energy required in Incremental Sheet Forming is as very much low than traditional forming processes.

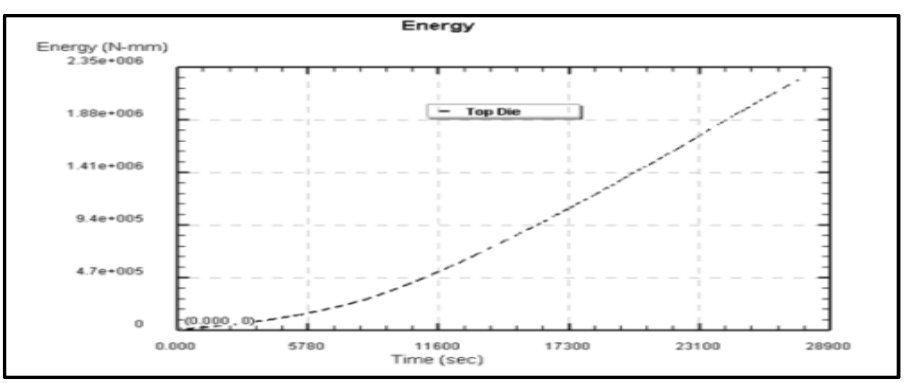

Figure 12: Energy Requirement

\section{Effective Stresses}

The very low effective stresses have been observed in Incremental Sheet Forming as shown in Fig 13. The effective stresses are found to increase with time. 


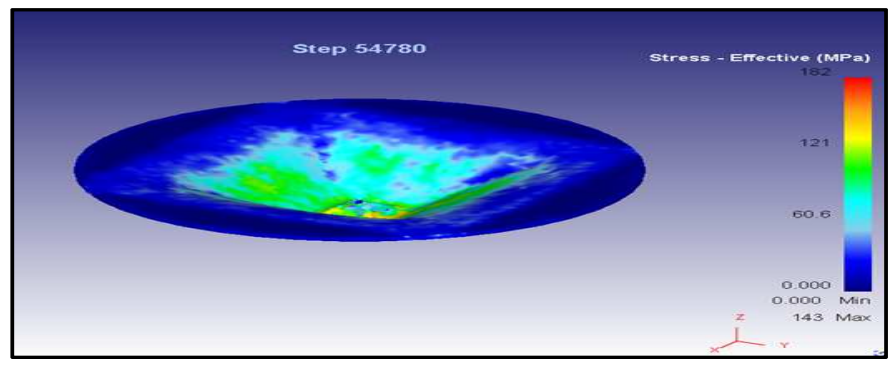

Figure 13: Effective Stress

\section{Total Force on Sheet}

The total forming forces observed on the sheet is shown in Fig 14. The local deformation results in a reduction in total force observed in incremental sheet forming.

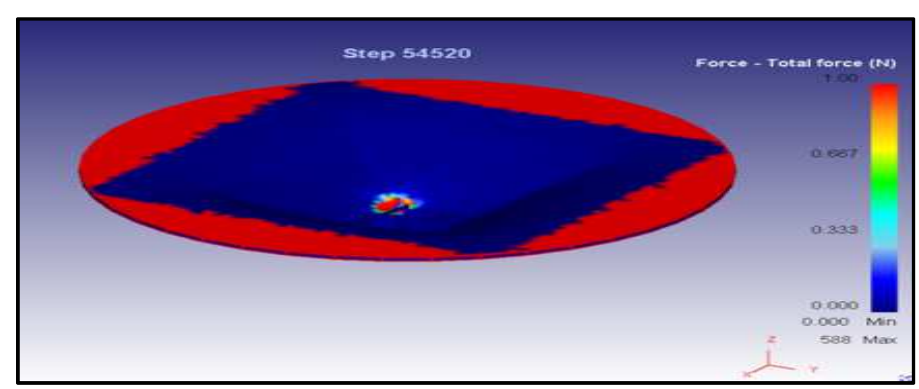

Figure 14: Total Force (N)

\section{Geometric Accuracy}

The geometric accuracy is an important issue in forming processes. The folding angle has been chosen to observe the geometric accuracies in incremental sheet forming. Thus, the geometric accuracy in incremental sheet forming process is found to be satisfactory as shown in Fig 15.

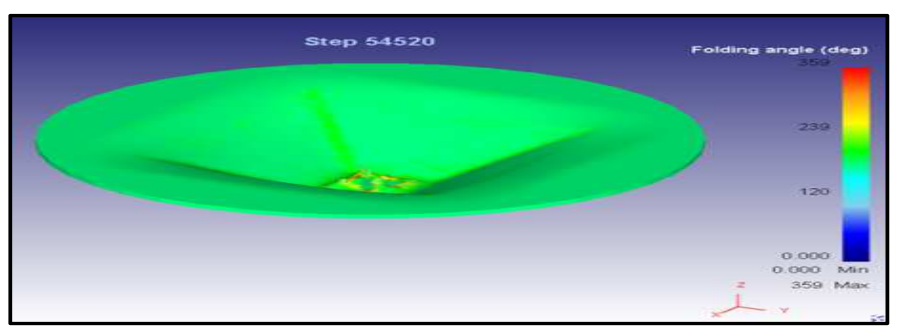

Figure 15: Folding Angle

\section{CONCLUSIONS}

- The forming forces in incremental sheet forming are very low when as compared to forming forces in traditional forming processes.

- The energy required in Incremental Sheet Forming is as very much lower than traditional forming processes and increases linearly with time.

- Very low effective stresses have been observed in Incremental Sheet Forming.

- The local deformation results in a reduction in total force observed in incremental sheet forming. 
- The geometric accuracy in incremental sheet forming process is found to be satisfactory.

\section{ACKNOWLEDGEMENTS}

Authors are grateful to IIT Kanpur and DRDL Hyderabad or providing assistance to carry out this research work.

\section{REFERENCES}

1. Ai, S., Lu, B., Chen, J., Long, H., Ou, H., 2017. Evaluation of deformation stability and fracture mechanism in incremental sheet forming. International Journal of Mechanical Sciences 124-125, 174 - 184.

2. Baruah, A., Pandivelan, C., Jeevanantham, A., 2017. Optimization of aa5052 in incremental sheet forming using grey relational analysis. Measurement 106, $95-100$.

3. Borrego, M., Morales-Palma, D., Martnez-Donaire, A., Centeno, G., Vallellano, C., 2016. Experimental study of holeflangingby single-stage incremental sheet forming. Journal of Materials Processing Technology 237, 320 - 330.

4. Cao, T., Lu, B., Ou, H., Long, H., Chen, J., 2016. Investigation on a new hole-flanging approach by incremental sheetforming through a featured tool. International Journal of Machine Tools and Manufacture 110, 1 - 17.

5. Centeno, G., Silva, M., Cristino, V., Vallellano, C., Martins, P., 2012. Hole-flanging by incremental sheet forming. International Journal of Machine Tools and Manufacture 59, 46-54.

6. Durante, M., Formisano, A., Lambiase, F., 2018. Incremental forming of polycarbonate sheets. Journal of MaterialsProcessing Technology 253, $57-63$.

7. Hesse, D., Hoppe, F., Groche, P., 2017. Controlling product stiffness by an incremental sheet metal forming process. Procedia Manufacturing 10, 276 - 285, 45th SME North American Manufacturing Research Conference, NAMRC45, LA, USA.

8. Kumar, S., Kumar, Y., Aug. 31 2016. Incremental sheet hydroforming machine. IN Patent App. 3312/DEL/2,014.

9. Kumar, Y., Kumar, S., 2015. Incremental sheet forming (isf). In: Advances in Material Forming and Joining. Springer, New Delhi, pp. 29-46.

10. Li, P., He, J., Liu, Q., Yang, M., Wang, Q., Yuan, Q., Li, Y., 2017. Evaluation of forming forces in ultrasonic incrementalsheet metal forming. Aerospace Science and Technology 63, $132-139$.

11. Min, J., Kuhlenktter, B., Shu, C., Strkle, D., Thyssen, L., 2018. Experimental and numerical investigation on incrementalsheet forming with flexible die-support from metallic foam. Journal of Manufacturing Processes 31, 605 - 612.

12. SAI, P. SRINIVASA, et al. "Chemical reaction and radiation effects on MHD flow over an exponentially stretching sheet with viscous dissipation and heat generation." Int. J. Math. Comput. Appl. Res 5.3 (2015): 35-48.

13. Okada, M., Kato, T., Otsu, M., Tanaka, H., Miura, T., 2018. Development of optical-heating-assisted incremental forming method for carbon fiber reinforced thermoplastic sheetforming characteristics in simple spot-forming and twodimensionalsheet-fed forming. Journal of Materials Processing Technology 256, 145 - 153.

14. Suresh, K., Nasih, H., Jasti, N., Dwivedy, M., 2017. Experimental studies in multi stage incremental forming of steel sheets. Materials Today: Proceedings 4 (2, Part A), 4116 - 4122, 5th International Conference of Materials Processingand Characterization (ICMPC 2016).

15. Thyssen, L., Magnus, C. S., Strkle, D. D., Kuhlenktter, B., 2017. Compensating geometric inaccuracies in incremental sheet forming at elevated temperatures. Procedia Engineering 207, 860 - 865, international Conference on the Technologyof Plasticity, ICTP 2017, 17-22 September 2017, Cambridge, United Kingdom. 
16. Wang, J., Nair, M., Zhang, Y., 2016. An efficient force prediction strategy in single point incremental sheet forming. Procedia Manufacturing 5, 761 - 771, 44th North American Manufacturing Research Conference, NAMRC 44, June 27 - July 1, 2016, Blacksburg, Virginia, United States. 